\title{
Analysis of the prospective energy interconnections in Northeast Asia and development of the data portal
}

\author{
Andrey Churkin ${ }^{1, *}$, Janusz Bialek ${ }^{1}$ \\ ${ }^{1}$ Skolkovo Institute of Science and Technology (Skoltech), Center for Energy Systems, \\ 143026 Moscow, Russia
}

\begin{abstract}
Development of power interconnections in Northeast Asia becomes not only engineering but also a political issue. More research institutes are involved in the Asian Super Grid initiative discussion, as well as more politicians mention power interconnection opportunities. UNESCAP started providing a platform for intragovernmental discussion of the issue. However, there are still a lack of comprehensive modern research of the Asian Super Grid. Moreover, there is no unified data base and no unified power routes concept. Therefore, this article discusses a tool for optimal power routes selection and suggest a concept of the unified data portal.
\end{abstract}

\section{Introduction}

The idea of creation Asian Super Grid (also mentioned as Asian Super Ring) as well as initiatives of direct power export from Russia to the Republic of Korea and Japan are not new. The issue of Asian Super Grid creation was mentioned by RAO UES (Unified Energy System of Russia) in 1998-2000. Options of direct power export to Japan were also considered. In 2003 RAO UES has signed memorandum of understanding with Japanese corporation Sumitomo. The necessity of Asian Super Grid development was mentioned several times by president Vladimir Putin at Asia-Pacific Economic Cooperation (APEC) forum and economic forum in Vladivostok. The president of Russian Federation expressed his support of Russian and foreign initiatives of energy integration and suggested to create a working group.

In recent 15 years several researches and analysis were performed on the Asian Super Grid. Most of them are listed in [1]. There also should be mentioned Skoltech research on power export options to the Republic of Korea and Japan, ESI SB RAS research on Asian Super Grid effectiveness and Gobitec project analysis [2], and recent researches of Renewable Energy Institute, Japan. At the Joint Conference on Northeast Asia Regional Power Interconnection 2017 it was shown that many other institutes and companies perform their own studies and analysis on power interconnections in Asia: Korea Electric Power Corporation KEPCO, Inner Mongolia Power Group, NovaTerra LLC, China Electric Power

\footnotetext{
*Corresponding author: andrey.churkin@skolkovotech.ru
} 
Planning \& Engineering Institute, Korea Electrotechnology Research Institute (KERI), and others.

However, there is no unified scheme (power interconnection routes) in researches mentioned. A difficulty exists in comparing the researches and initiatives due to lack of open information. This article suggests a tool for optimal power interconnection routes selection and data portal concept that contains information about all existing researches, analyses and initiatives of power interconnection. Development of such portal will aggregate information and present it form accessible even to non-technical people, promoting the Asian Super Grid project.

\section{Analysis and simulation of existing power systems}

Even though there are few considerable interstate power interconnections in Northeast Asia (only Russia-China power export via $500 \mathrm{kV}$ line is significant), each solitary power system has already been formed, has its own topology, features and issues. High level researches performed suggest power interconnections arbitrarily in order to estimate approximate cost of the project. There is no analysis of optimal power interconnection routes and possible regimes. Such analysis requires accurate simulation of existing power systems.

We suggest model development of each Northeast Asian power system taking into account HV and UHV power lines. This kind of modelling has been successfully performed by professor J. Bialek in case of European Union [3]. The direct current (DC) model was composed on the basis of publicly available information. Then, simulated power flows were compared with actual power flows on a certain date. Average accuracy was over $90 \%$. The model was later used by consulting agencies and institutes, particularly for renewable power sources integration effect analysis.

Skoltech started simulating North and Northeast power systems of China (fig. 1) because these regions would be the main chain of the Asian Super Grid, interconnecting Russia, Mongolia and Korea. The model is being composed on the basis of available information on power systems topology, demand and generation. At this stage the model contains 170 buses, 360 lines, 110 generators and 150 loads.

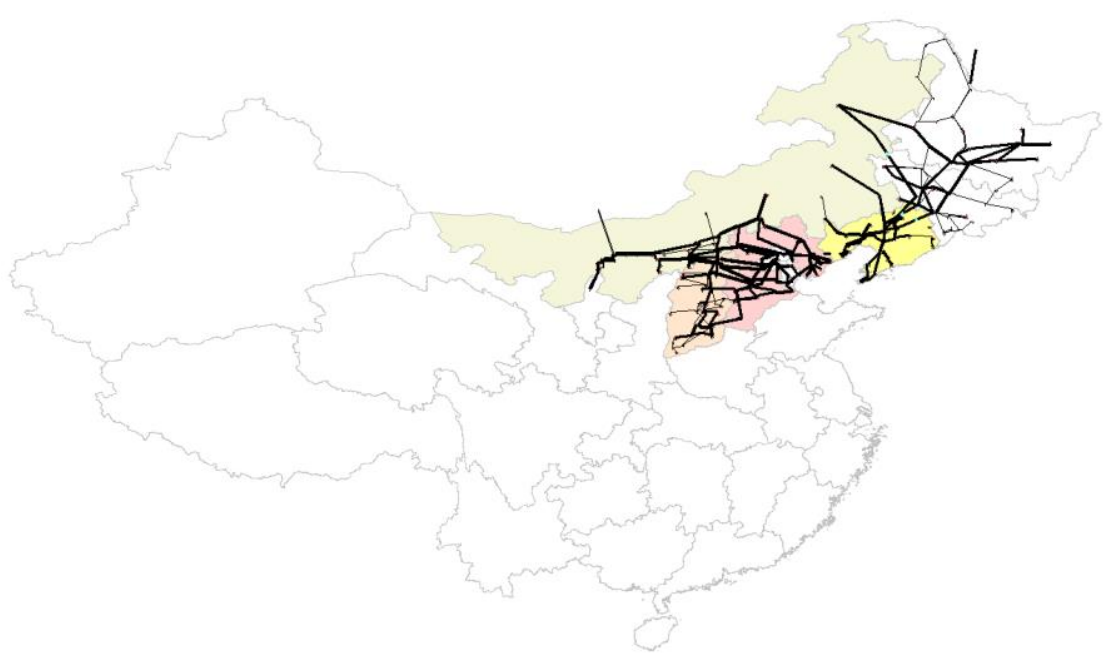

Fig. 1. North and Northeast Chinese power systems model 
However, accuracy of the model is unsatisfactory. It can be stated that only directions of power flows do match to State Grid Corporation of China reports. Unsatisfactory results can be explained by:

- lack of publicly available information (most of the reports are not available or written only in Chinese),

- rapidly developing power system (dozens of HV and UHV power lines are planned or already under construction in China that makes available power system schemes outdated; each new powerful line changes power flow distribution significantly),

- features of the Chinese economy (highly industrialized country; huge amount of powerful factories; missing/neglecting one of the powerful loads decrease accuracy of the model).

Therefore, simulation of Northeast Asia power systems is a complex task that should be performed jointly by international institutes and companies. The model will enable to select optimal power interconnections, analyse power regimes, detect power systems bottlenecks, analyse effect of renewable generation injection, etc. Thus, the unique powerful tool can be developed that will bring Asian Super Grid researches to a new level.

\section{Data portal concept}

As was mentioned above, discussions and studies of power interconnections in Northeast Asia are performed for more than 15 years. However, there is still no unified concept of power interconnections. There is a lack of publicly available information. Results of the researches performed are not easy to find and compare. Therefore, it is hard to convince common people in Asian Super Grid project necessity and effectiveness.

Together with UN ESCAP Energy Division we developed a concept of Energy Connectivity data portal, containing all relevant up-to-date information about power interconnection initiatives. The concept can become the new section of already existing portal http://www.asiapacificenergy.org/ that aggregates reliable statistics and information about energy development in Asia and the Pacific regions. The new section will contain subsections that show power systems development, forecasts and initiatives of power interconnection. Concept of these subsections are presented below.

\subsection{Power systems development map}

The concept of power systems development map implies presentation of each power system as a circle with square proportional to total annual electricity production and demand (sum of power generation TWh and power demand TWh). Moreover, each circle can be divided as a pie chart in order to show the ratio of generation and consumption. The next pie chart around the circle shows ratio of primal energy resources import/export/production. The bar chart near the circle shows comparison of installed capacity and peak demand in a certain power system. Finally, the money bar shows an average electricity price in a system.

Once user opens the power systems development map, all necessary explanations should be provided. An enlarged example of power system charts and bars is presented in figure 2 . The concept of power systems development map in case of Northeast Asia in shown in figure 3. The charts and bars represent data from 2013. Thus, power systems development map enables even non-technical users to compare different power systems, examine electricity prices and dependence on energy import. Moreover, the map will contain timeline that allows to examine power systems retrospective and forecast for future development. 


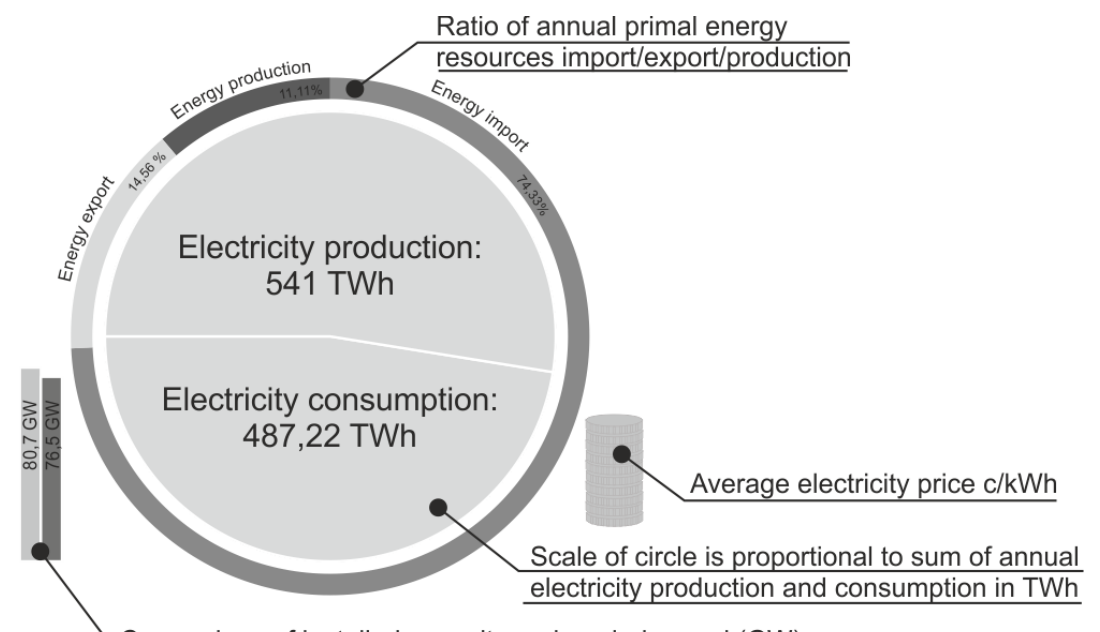

Comparison of installed capacity and peak demand (GW)

Fig. 2. Description of power system charts and bars

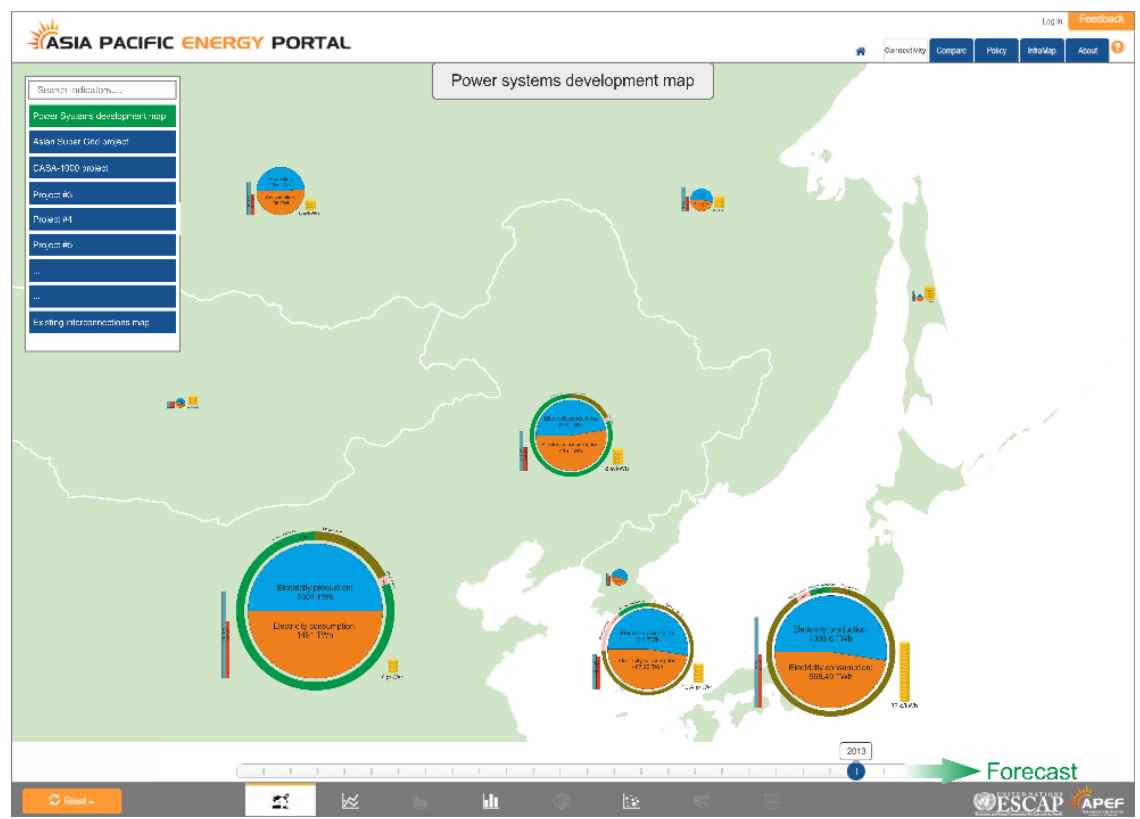

Fig. 3. Concept of the power systems development map

\subsection{Project mapping}

Despite power systems development map Energy Connectivity section will contain the list of existing projects of power interconnection in Asia. Each project involves at least several countries. Once user selects a certain project an interactive map opens allowing user should to examine initiatives of each country and results of researches on current integration project. There should be an option to switch on any layer of a project or all layers together.

There are numerous parameters that can be shown for a country in order to promote energy integration project. Moreover, these parameters are not the same for different countries. Some countries do not disclose information that their neighbors do. Most of the 
parameters can be presented in form of diagrams. Scheme of suggested interconnections can be shown on a map with explanations provided.

Analysis of power systems have been performed for Northeast Asia countries in order demonstrate necessity of the Asian Super Grid project, the most ambitious one. Information is shown county by county, as it would be in the Energy Connectivity portal.

\subsubsection{The Republic of Korea}

Considering the Republic of Korea high dependence on energy import should be mentioned (figure $4 \mathrm{a}$ ). Through the last decade Korean rate of dependence in final energy consumption exceeded 95\% [4]. The main energy import products are crude oil, coal, natural gas and oil products. Moreover, Korea has the highest rate of electricity consumption per capita Asia (figure 4b). Along with high rate of import dependence, this poses serious issues of energy security. In addition, electricity price is rather high [5] (figure 5b). Under these circumstances, Korea turns its attention towards renewable energy. In preliminary version of the $8^{\text {th }}$ basic plan for long-term Electricity Supply and Demand it is suggested to phase out nuclear power by renewables whose share can reach $20 \%$ of total generation by 2030 (figure 5a).

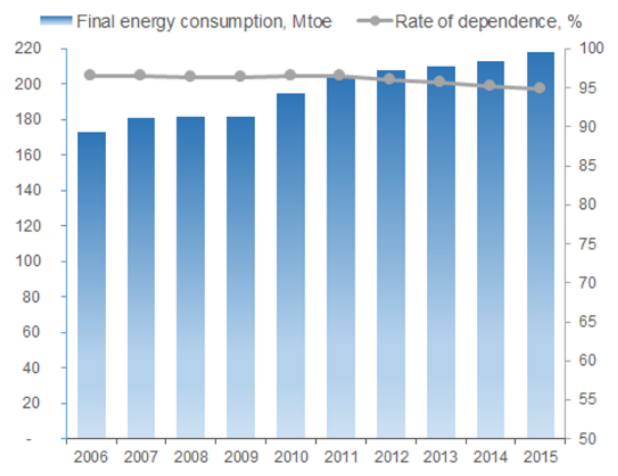

(a)

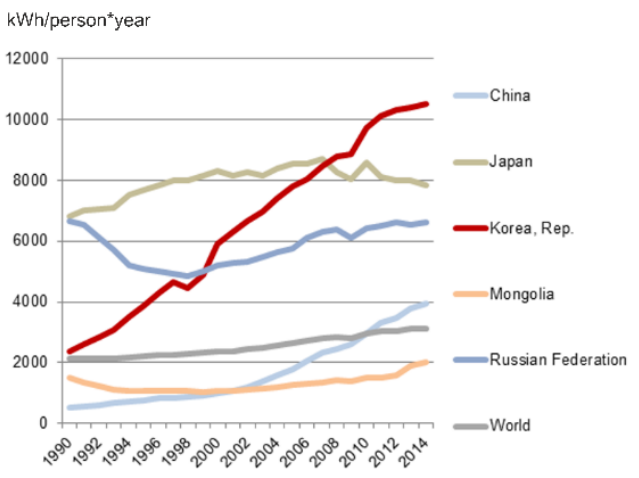

(b)

Fig. 4. Korean energy consumption and dependence on import (a), electricity consumption per capita (b)

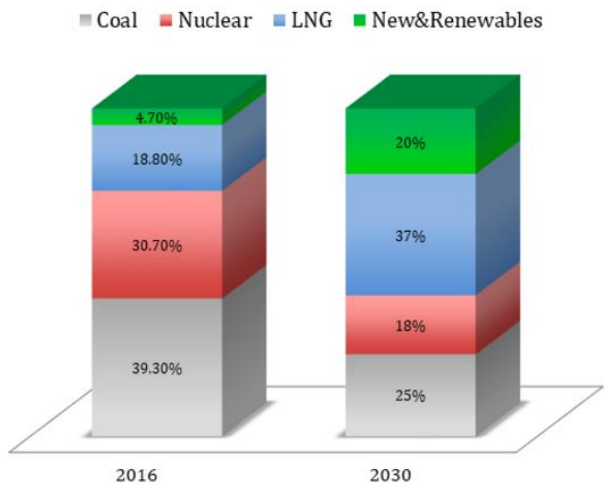

(a)

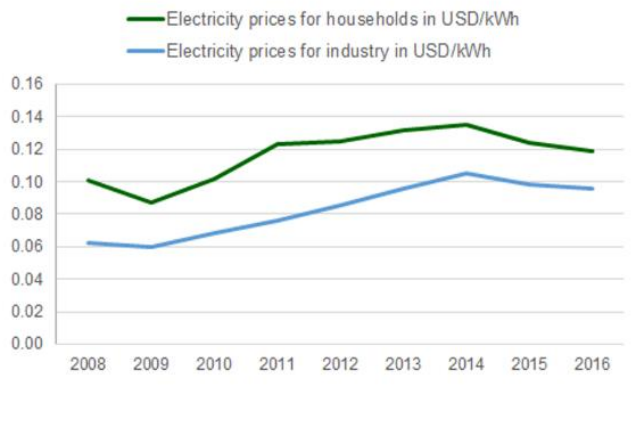

(b)

Fig. 5. Korean energy policy shift (a), electricity prices (b) 
Such significant increase in renewable generation share will influence power system operation and stability. The obvious measure of stability enhancement is interconnection with neighboring power systems. Therefore, possible options of interconnection have been studied (figure 6). The main routes are presented in the figure 6. However, most of the studies considered power lines construction through the Korean peninsula that cannot be achieved due to political issues. Recent studies suggested undersea cables construction to China and Japan. Preliminary assessment performed by KEPCO showed that $2 \mathrm{GW}$ undersea interconnection China-Korea-Japan would cost 6 bln. \$.

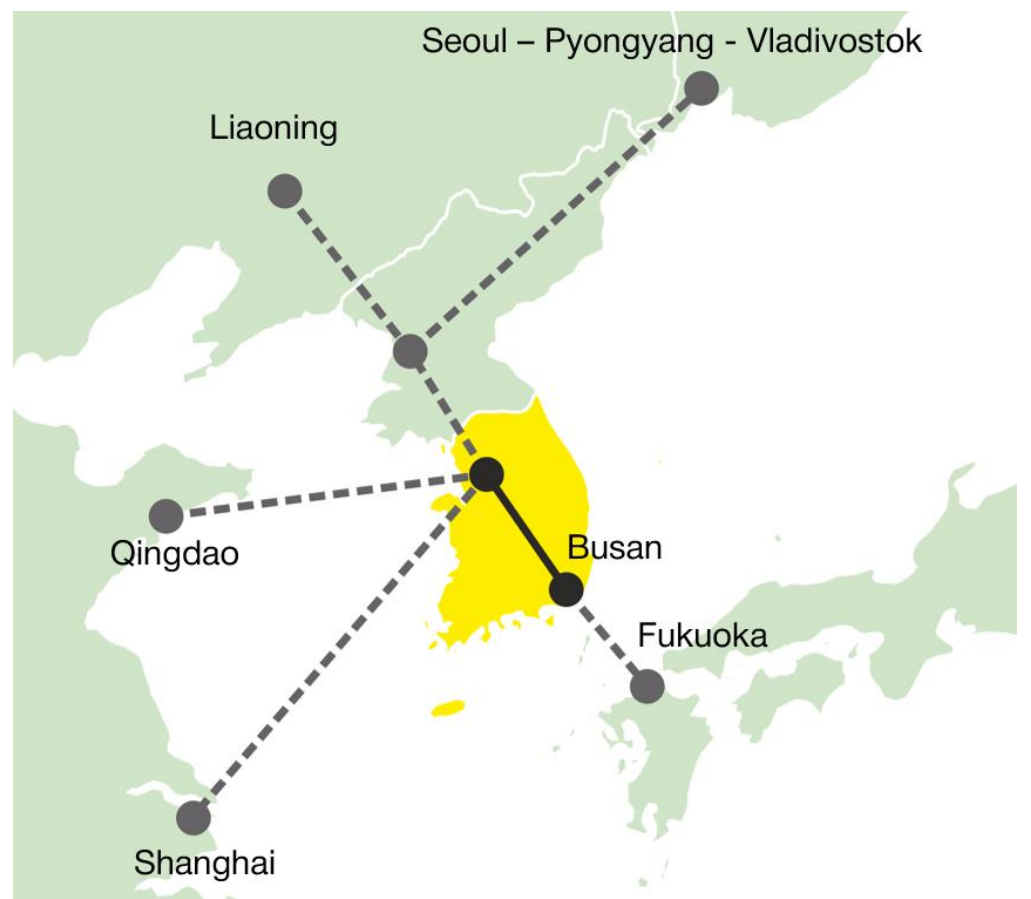

Fig. 6. Possible routes of power interconnection with the Republic of Korea

\subsubsection{Japan}

Japan is in similar conditions as the Republic of Korea being one of the most energy dependent countries in the world [6] (figure 7a). Electricity price in Japan is even higher than in Korea [5] (figure 7b). Therefore, Japan is also interested in renewable energy development that is presented in Long-term Energy Supply and Demand Outlook 2015 [7] (figure 8). It seen that Japan takes significant conservation measures in order to restrict power demand growth. Moreover, it is anticipated that annual power demand growth would start declining by 2030 and would be $-1.2 \%$. Regarding power source mix, Japan also forecasts significant increase of renewable energy up to $19-20 \%$ of total generation by 2030 .

It is natural that power interconnection with neighboring countries have been considered. Possible routes of interconnections with Korea, Japan and Russia are presented in figure 9. Construction of the power interconnection would alleviate Japan primal energy resource dependency and positively influence on electricity price. However, each interconnection project needs precise technical and economic assessment. 


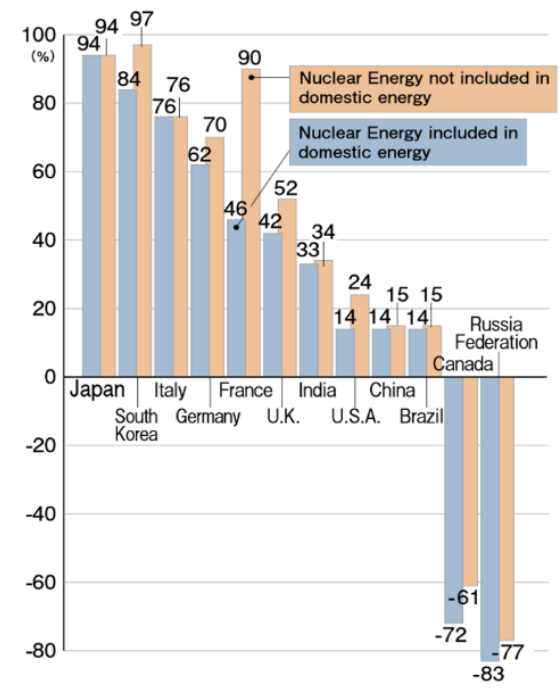

(a)

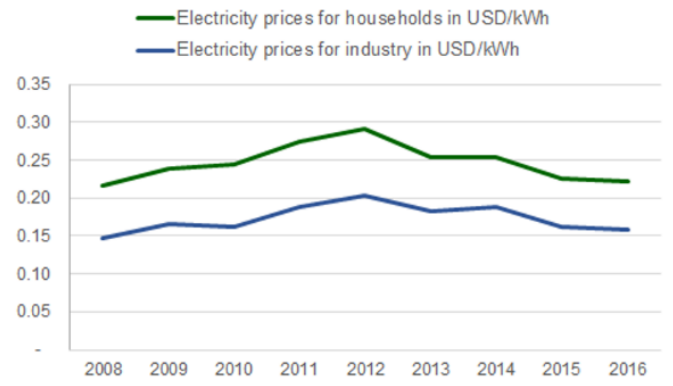

(b)

Fig. 7. Japan dependence on imported energy sources (a), electricity prices (b)

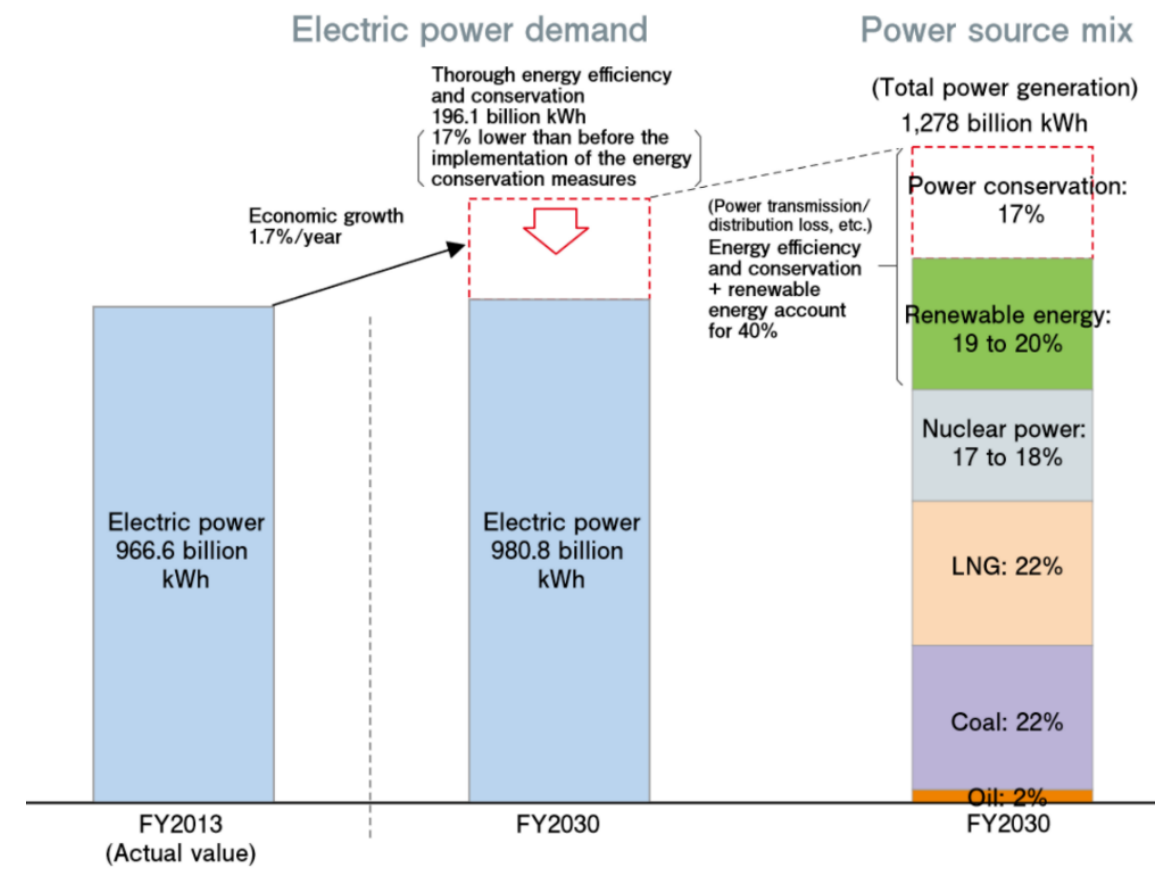

Fig. 8. Japan Long-term Energy Supply and Demand Outlook 2015 


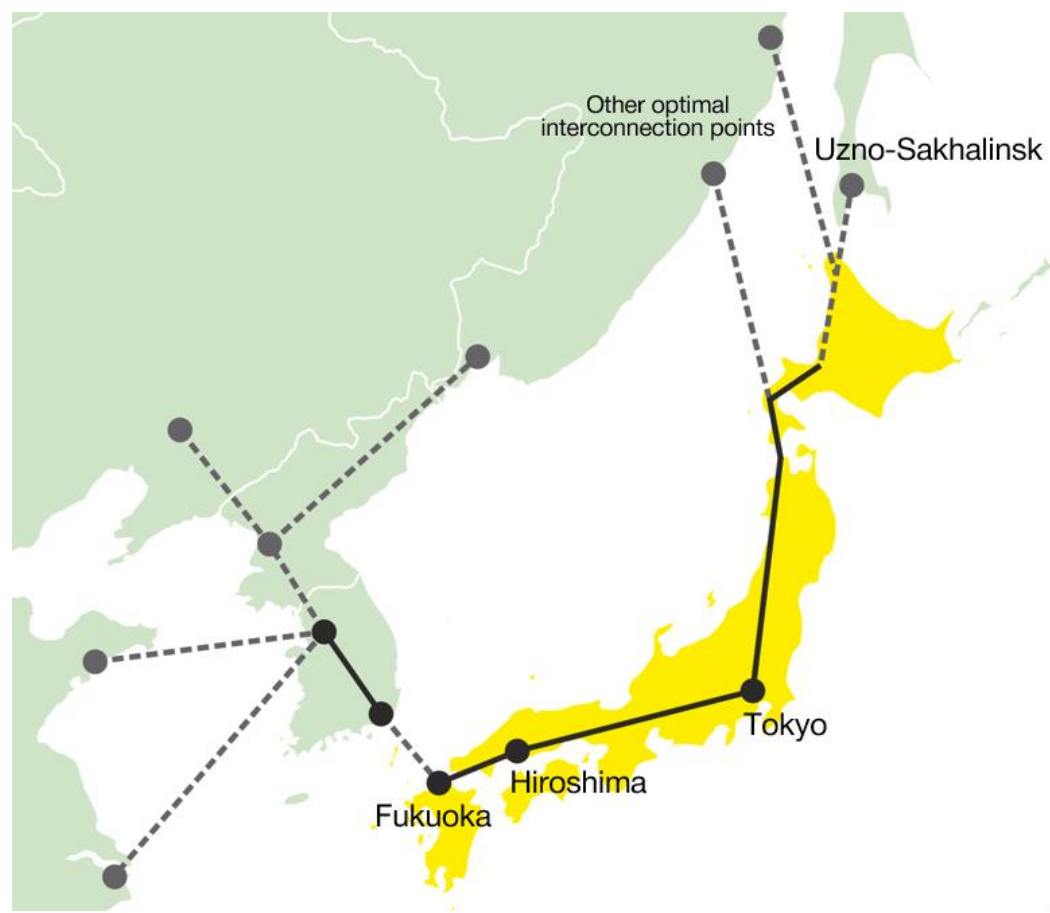

Fig. 9. Possible routes of power interconnection with Japan

\subsubsection{People's Republic of China}

It is hard to imagine interstate power interconnections in Asia without China whose power system development pace is outstanding. Total installed capacity growth of Chinese power system is presented in figure 10 [8]. The $13^{\text {th }}$ Five-Year-Plan forecasts annual energy consumption growth by $2.5 \%$, electricity consumption growth by $3.6-4.8 \%$ and GDP growth by $6.5-7 \%$.

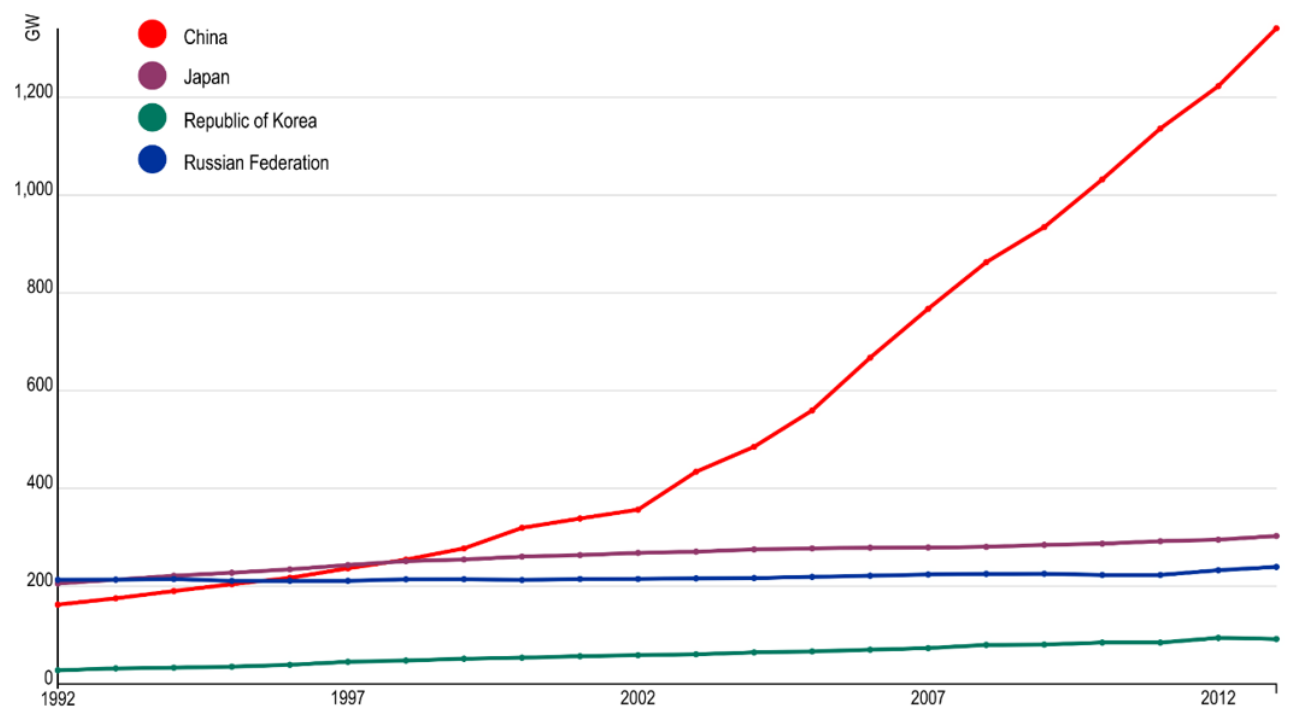


Fig. 10. Total installed power plant capacity statistics

China possesses high-developed energy infrastructure with more than $640000 \mathrm{~km}$ of HV and UHV power lines. There also are existing interconnections with Mongolia and Russia. The infrastructure mentions creates an advantageous conditions for interstate power interconnection. Possible routes of power interconnection with China are presented in figure 11. It should be mentioned that China also develops renewable energy: the $13^{\text {th }}$ Five-YearPlan implies huge investment in hydro power and renewable energy up to 370 bln. \$ by 2020 .

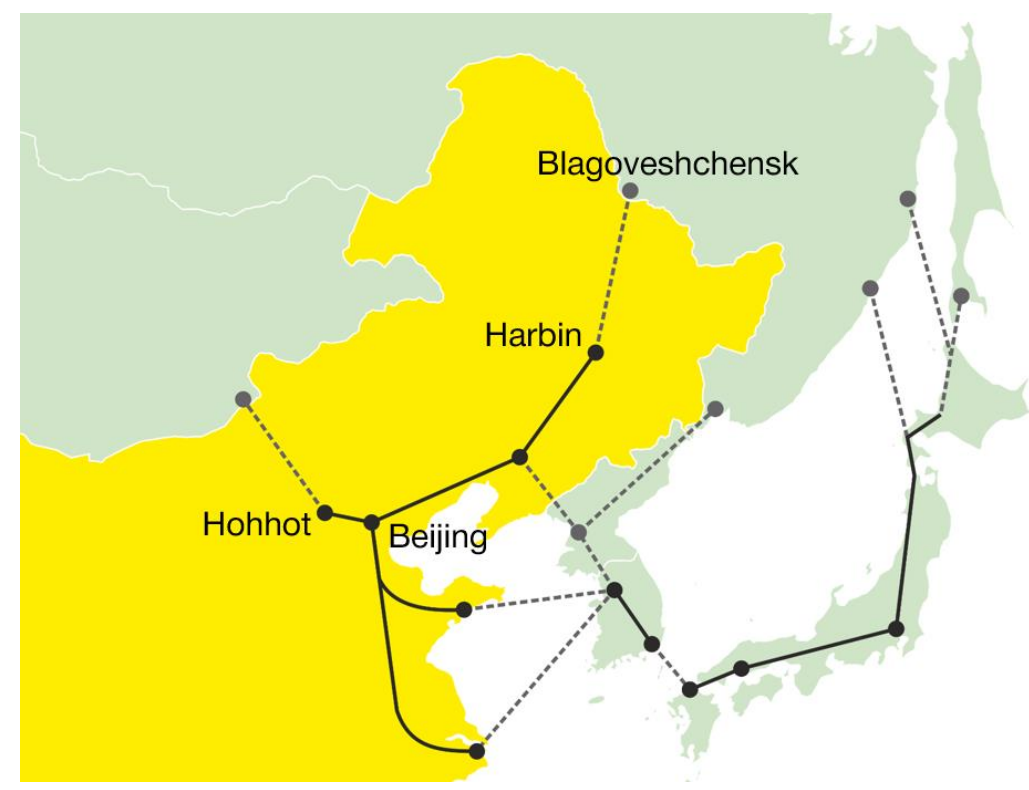

Fig. 11. Possible routes of power interconnection with China

\subsubsection{Mongolia}

Mongolian power system is small compared to neighboring systems. It possess $1.2 \mathrm{GW}$ of installed capacity and is divided into 5 separate power systems. There is power import both from China and Russia. Nevertheless, Mongolia is interested in power interconnection due to its geographic position and renewable energy potential: Gobitec initiative implies renewable power sources creation in the Gobi Desert with installed capacity exceeding $100 \mathrm{GW}$.

Possible power interconnection would connect China and Russian Ulan Ude through Ulaanbaatar and Gobi Desert. This interconnection would enhance Mongolian power system stability and pave a way for renewable energy export.

\subsubsection{The Russian Federation}

Three Russian power systems are usually considered during Northeast Asia power interconnections discussion: Siberian power system, power system of the Far East and Sakhalin power system. The main point for participation in the integration projects is Russian huge hydro potential, especially in Siberia, and relatively low electricity price. Even nowadays, there is significant amount of power reserve and unrealized reserve in Siberia and the Far East: 7.1 GW and 4.1 GW consequently [9]. 
Installed capacity of Siberian power system and the Far East power system in 2017 reaches 51,97 GW and 9,19 GW respectively. Hydro power share reaches 49\% in Siberian power system and $36 \%$ in the Far East power system. There are dozens of power plants construction projects and initiatives by "Rushydro", "InterRAO", "Eurosibenergo" that can increase installed capacity of Siberian power system up to $67,3 \mathrm{GW}$ and capacity of the Far East power system up to $16,1 \mathrm{GW}$ by 2035 (according to joint Skoltech - ESI SB RAS research, 2015). Installed capacity of Sakhalin power system can increase from $850 \mathrm{MW}$ up to $1290 \mathrm{MW}$ by 2035 .

There is significant infrastructure in Sibria and the Far East (figure 12), as well as existing interconnections between Russia and China, Russia and Mongolia. The Far East power system is connected to Northeast China by 3 power lines: $110 \mathrm{kV}, 220 \mathrm{kV}$ and $500 \mathrm{kV}$ that enables to export more than $3 \mathrm{bln}$. $\mathrm{kWh}$ per year. Power export from Siberia to Mongolia is less significant: there is $220 \mathrm{kV}$ line with maximum transmission capacity $245 \mathrm{MW}$.

As an energy exporting country Russia has an obvious interest in Asian energy integration. Moreover, Russian geographical position enables to interconnect most of the Asian Northeast countries. Existing infrastructure and excessive capacity makes it real to discuss power export options in the foreseeable future.

\subsubsection{Asian Super Grid}

After analysis of each country's power system and initiatives of interconnection, it is possible to present the entire scheme of the project (figure 12) that encompasses the Republic of Korea, Japan, China, Mongolia, Russian Siberia, the Far East and Sakhalin. Kazakhstan can also be included due to its proximity and Russia-Kazakhstan existing interconnection.

Subsections with existing interstate power interconnections and results of researches performed should be presented. Figure 13 shows economic benefits estimated by joint Skoltech - ESI SB RAS research.

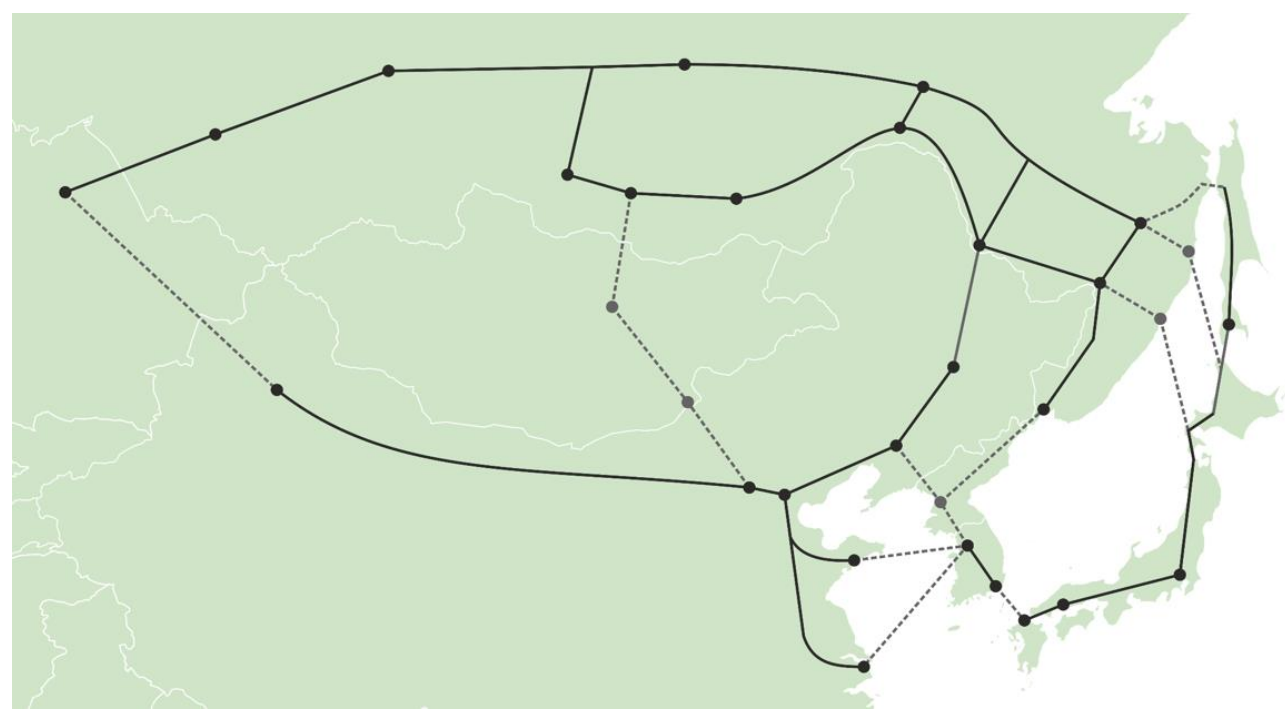

Fig. 12. Scheme of the Asian Super Grid project 


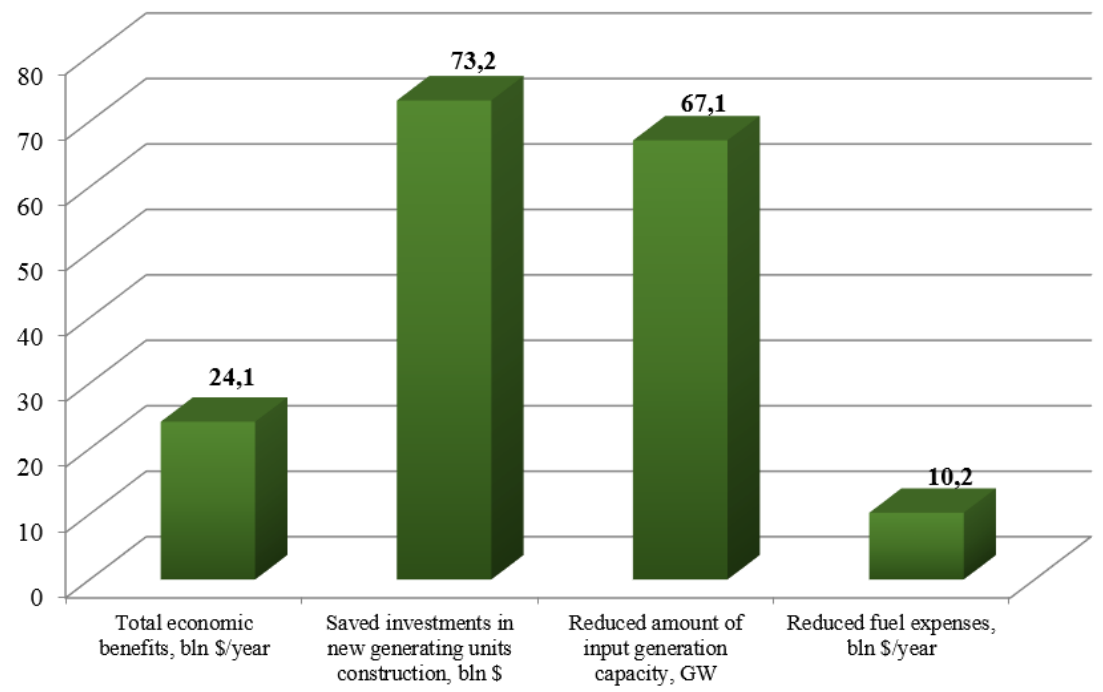

Fig. 13. Economic effects of the energy integration by 2035

\section{Conclusion}

Analysis of Northeast Asia counties' power system has been performed. Energy Connectivity data portal concept was presented. It is suggested that aggregation of power interconnection initiatives and results of research would promote power interconnection projects in Asia. Development of Northeast Asia power systems model would facilitate further research of energy connectivity issues.

\section{References}

1. Takashi Otsuki, Aishah Binti Mohd Isa, Ralph D. Samuelson, "Electric power grid interconnections in Northeast Asia: a quantitative analysis of opportunities and challenges", Energy Policy 89 (2016), pp. 311-329

2. "Gobitec and Asian super grid for renewable energies in Northeast Asia", ISBN 978-905948-143-5

3. Neil Hutcheon, Janusz W. Bialek, "Updated and validated power flow model of the main continental European transmission network", PowerTech (POWERTECH), 2013 IEEE Grenoble

4. "Yearbook of Energy Statistics", Korea Energy Economics Institute (KERI), ISSN 1226-606X, 2016

5. "Energy prices and taxes", International Energy Agency, ISSN 1609-6835, 2017

6. “Energy Balances of OECD Countries 2015 Edition”, International Energy Agency

7. “Long-term Energy Supply and Demand Outlook 2015”, Ministry of Economy, Japan, 2015

8. http://www.asiapacificenergy.org/, Energy Statistisc Database, United Nation Statistics Division

9. “Analysis of power balances” System Operator report (www.so-ups.ru), Q1 2017 